\title{
Disseminação de Informações no Twitter: uma análise sobre o debate eleitoral dos presidenciáveis de 2018 no Brasil
}

\section{DISSEMINATION OF INFORMATION ON TWITTER: AN ANALYSIS OF THE ELECTORAL DEBATE OF 2018 PRESIDENTIAL CANDIDATES IN BRAZIL}

\section{Alan César Belo Angeluci ${ }^{1}$}

ORCID: https://orcid.org/0000-0002-4093-0590

(Universidade Municipal de São Caetano do Sul, Programa de Pós-Graduação em Comunicação. São Caetano do Sul - SP, Brasil).

Matheus Felske da Silva ${ }^{2}$

ORCID: https://orcid.org/0000-0001-7684-1795

(Universidade Municipal de São Caetano do Sul, Programa de Pós-Graduação em Comunicação. São Caetano do Sul - SP, Brasil). 


\section{Resumo}

Este artigo aborda a disseminação de mensagens no Twitter e os papéis de seus atores em torno do último debate dos candidatos a presidência do Brasil de 2018. Ampara-se na formação da estrutura da rede com base em postagens sobre o debate, em especial na identificação dos principais atores e das diferentes funções exercidas pelos usuários que tuitaram sobre o evento. Os resultados apontam a relevância da imprensa na produção de conteúdos, agregada ao papel fundamental de usuários comuns no sentido de espalhar o conteúdo produzido por estes veículos.

Palavras-chave: Análise de Redes Sociais. Papel dos Usuários no Twitter. Debate dos Presidenciáveis 2018.

\section{Introdução}

A partir da aplicação de métodos e técnicas de Análise de Redes Sociais (ARS), este estudo teve como objetivo investigar a ação de usuários do Twitter e sua interação com conteúdos televisivos, especificamente o último debate do primeiro turno entre os candidatos à presidência do Brasil nas eleições de 2018. O pleito foi marcado pelo protagonismo das redes sociais virtuais no agendamento das mídias e na formação da opinião pública. A escolha do Twitter para a coleta e análise de dados deve-se a sua configuração nos últimos anos como um importante espaço de manifestações políticas, tanto por parte dos candidatos, com o propósito de divulgar compromissos e opiniões, como pelos eleitores, que reagem ativamente as tomadas de decisão dos aspirantes a governantes. Ademais, esta rede social virtual confere maior facilidade na extração das informações em comparação com as demais existentes, o que incentiva a investigação em torno de seus atores.

Em um cenário onde as múltiplas telas e as redes sociais virtuais estão cada vez mais integradas ao cotidiano dos indivíduos, selecionou-se o último debate dos candidatos à Presidência do Brasil, tradicionalmente realizado pela TV Globo, que pode ser considerado como um dos principais espaços de definição de intenções de voto. Dessa 
forma, o debate realizado no dia 4 de outubro de 2018, que ocorreu três dias antes do primeiro turno das eleições, foi o escolhido para a coleta e análise de sua repercussão e discussão no Twitter, com possibilidade de gerar um grande potencial de controvérsias na rede.

Nessa perspectiva, o Twitter tem se mostrado um espaço relevante na repercussão de questões políticas divulgadas pelos meios de comunicação, a exemplo da replicação de mensagens, que se revela como uma forma de ampliar as relações, partilha ou interação entre os usuários desta rede (ROSSETTO; CARREIRO; ALMADA, 2013). Logo, as redes sociais na atualidade parecem constituir-se como mais um meio de divulgação da opinião disseminada nas mídias tradicionais, seja pelo compartilhamento de links com textos de jornais, programas de TV e rádio, ou no agendamento destes (BARRIGA, 2015).

Assim, esta investigação buscou identificar a cartografia gerada por usuários do Twitter durante o debate na TV, bem como analisar as reações na rede por ocasião de algumas discussões de maior destaque. Também, foram evidenciados os agrupamentos da rede, temas e termos mais abordados e papéis exercidos por usuários ${ }^{3}$.

\section{Sites de Redes Sociais: Espaços de Informação Política}

O advento das novas tecnologias de informação e comunicação, sobretudo no começo do século XXI, possibilitou o surgimento de novos mecanismos de articulação e mobilização social, derivados da disseminação do acesso aos dispositivos móveis e redes sociais on-line (ANTOUN; FALCÃO, 2015). Com isso, pessoas comuns passaram a produzir os próprios conteúdos, com possibilidades de alcançar grandes audiências, dividindo espaço com as mensagens dos meios de comunicação tradicionais. Para Duarte, Rivoire e Ribeiro (2016), a liberdade que os usuários têm de escolher e divulgar os conteúdos entre grupos de relacionamentos, faz com que se privilegie o uso de linguagens próprias, características da sua rede de contatos, não tendo interesse em reproduzir o modelo da mídia tradicional. Antoun e Falcão (2015, p. 150) avaliam:

O que muda quando a sociedade passa a ter acesso também aos conteúdos criados livremente, de fontes alternativas, sem ligação direta com empresas ou corporações, conteúdos criados por apenas cidadãos? Muda, em primeiro lugar, a opinião pública.

\footnotetext{
${ }^{3}$ A presente pesquisa foi desenvolvida com o apoio do então aluno Andreas Dominguez, sendo parte de seu trabalho de conclusão de curso, orientado pelo professor Dr. Alan Angeluci. Foi posteriormente aprimorada para esta publicação.
} 
Se antes a população era considerada "massa de manobra" da chamada grande mídia, hoje os jovens ativistas de rua ou de sofá são legitimamente considerados criadores e distribuidores de conteúdo e informação [...].

No âmbito político, esse cenário é notório, uma vez que as redes sociais virtuais vêm se transformando em ambientes cada vez mais utilizados para a manifestação de opiniões e práticas democráticas. Segundo Zago (2016, p. 26), os "sites de rede social são ambientes propícios para se observar a circulação e a recirculação jornalística na medida em que os rastros desses processos se tornam visíveis ao se acompanhar as postagens feitas pelos usuários".

Diante da relevância desses espaços no cotidiano das pessoas, cabe ressaltar conceitos sobre redes sociais. Para Recuero (2009), apesar de ferramentas digitais como Facebook e Twitter serem comumente chamadas de redes sociais, não representam o sinônimo de rede social. Recuero (2017) explica que uma rede social pode vir a ser qualquer grupo de indivíduos que se relacionam entre si nos mais diferentes ambientes de sua vida, como família, amigos, escola e trabalho:

Essas relações são estabelecidas por interações e associações e vão conferir aos atores determinadas posições nas suas redes sociais, que vão sendo modificadas por essas mesmas ações. A posição desses atores é, ao mesmo tempo, produto e produtora de interações, ou seja, a rede influencia e é influenciada pela posição de seus usuários (RECUERO, 2017, $\mathrm{s} / \mathrm{p})$.

Com relação aos sites de redes sociais, Recuero (2009, p. 102) compreende como “espaços utilizados para a expressão das redes sociais na Internet”. Nessa linha, Santos e Santos (2014, p. 310) consideram como "um meio de possibilidades, estabelecido a partir dos elementos virtuais e das relações entre os indivíduos usuários". Zenha (2018, p. 25) define como "um ambiente digital em conexão no qual é possível observar o desenrolar, a evolução e a constante modificação dos embates psicossociais de seus integrantes, embates esses não apenas de ordem tecnológica, mas, sobretudo, humana".

Quanto a estrutura de um site de rede social, Recuero (2009) entende que é formada por atores e suas conexões. De acordo com Zago (2016, p. 29), “os atores são os nós da rede, indivíduos ou grupos que estão conectados a outros por alguma relação em comum". A autora compara essa estrutura com a profissão de jornalista: "em uma redação jornalística, cada profissional envolvido na produção de notícias pode ser considerado 
um nó, e as diferentes relações trabalhistas representam as conexões" (ZAGO, 2016, p. 29). Também pode-se apontar características que fazem parte da estrutura de uma rede social, como "a tendência à grupabilidade e os buracos estruturais" (RECUERO; ZAGO; SOARES, 2017, p. 5). A grupabilidade, para Recuero, Bastos e Zago (2015), trata-se do grau de conexão entre os nós. Já os buracos estruturais referem-se aos grupos de pessoas dentro de uma rede que não se comunicam (BURT, 1992).

A movimentação de atores nos sites de redes sociais em decorrência de uma programação televisiva, traz à tona a reflexão sobre a convergência das mídias na contemporaneidade e o uso de múltiplas telas. Nesse contexto, Angeluci (2015) expõe que a televisão, tida por décadas como o principal meio de comunicação social, está se reinventando com o surgimento das plataformas híbridas e interativas, e passa a dividir a atenção com os smartphones. Um reflexo dessa realidade foi a iniciativa de algumas emissoras que transmitiram debates eleitorais em 2018 de fazer parcerias com empresas de redes sociais virtuais, a fim de oferecer aos telespectadores/usuários experiências multiplataformas e participativas, como a RedeTV! e a Rede Bandeirantes.

\section{O Twitter e seus Principais Recursos}

O Twitter destaca-se como um dos mais importantes sites de redes sociais na atualidade e alcançou popularidade, segundo Barriga (2017, p. 29), por apresentar uma interface simples e explorar as características mais significativas da Web: "instantaneidade, interatividade, personalização, hipertextualidade, mobilidade e convergência". Um de seus principais recursos é o retuíte, que nos termos de Zago (2016), trata-se de uma ação relevante por reproduzir uma informação, alertando outras pessoas sobre acontecimentos. Nessa linha, Zago e Bastos (2013) entendem que a replicação das notícias a partir de retuítes promove visibilidade, já que os conteúdos passam a alcançar outros usuários, não necessariamente seguidores de seus autores originais. Dessa forma, Bruns e Burgess (2012, p. 3) apontam os internautas que retuítam como intermediários da informação, "conectando diferentes comunidades de interesse, que transmitem tweets de um cluster de rede para outro".

Outra característica do Twitter é a utilização de hashtags, que são formas de enquadrar um tweet dentro de um tema, funcionando como marcadores. Dessa maneira, qualquer usuário pode acompanhar toda a discussão on-line em torno de um fato específico. Além disso, as hashtags são aproveitadas como mecanismos para demonstrar 
apoio ou repúdio a alguma causa, o que, normalmente, é ditado por acontecimentos da atualidade. Bruns e Burgess (2012) explicam que a partir dessa opção os usuários podem interagir sobre diferentes assuntos sem a necessidade de seguir ou ser seguido por alguém. Assim, a partir da ARS, é possível identificar no Twitter usuários que exercem o papel de intermediários em determinadas discussões, hashtags ligadas aos temas, termos mais utilizados pelos usuários e a formação de comunidades que se agrupam por afinidades. Pode-se elencar também os usuários que mais recebem citações ou marcações e aqueles que mais tuítam novas informações.

Relativamente a política nesse site de rede social, percebe-se a massificação e a polarização de discursos, porém, aqueles que apresentam posições "extremadas, ofensivas, humilhantes e violadoras da democracia", estão sujeitos a receberem a rejeição dos usuários (BARRIGA, 2017, p. 31). A possibilidade de acompanhar os dizeres da população a respeito dos candidatos do país em que se vive, bem com as opiniões e agendas dos representantes do governo, transformou o Twitter em um forte meio para comunicação política, utilizado por partidos, organizações internacionais, agentes do terceiro setor e da sociedade civil, entre outros, sendo alvo de análises por profissionais e pesquisadores (CAMPOS-DOMÍNGUEZ, 2017). Portanto, é nele que este artigo se concentra, a fim de fornecer uma fotografia a respeito das ações de seus usuários quando do período eleitoral.

\section{Materiais e Métodos}

O presente estudo pode ser classificado como quantitativo e qualitativo, e utiliza elementos da Análise de Redes Sociais (ARS), como a mineração de dados e a identificação de características da rede, de seus atores e grupos sociais. No que se refere a etapa quantitativa, seguiu-se os preceitos de Benevenuto, Almeida e Silva (2011), que a dividem em quatro passos: extração, processamento, visualização e análise. Na extração, foi utilizada a ferramenta on-line Netlytic ${ }^{4}$, em sua versão de 2018, que possibilitou a coleta de dados do Twitter.

De forma gratuita, a Netlytic permite a extração de mil tuites feitos nos últimos 15 minutos, podendo indexar até 10 mil tuites em um mesmo banco de dados. Dessa forma, foi realizada a extração de 10 mil tuites contendo a hashtag DebatenaGlobo ao longo do último debate presidencial realizado na TV Globo no dia 04 de outubro de 2018, que começou às $22 \mathrm{~h} 00$ e teve aproximadamente $2 \mathrm{~h} 45$ de duração. As extrações foram

${ }^{4}$ Disponível em https://netlytic.org. 
realizadas em tempos espaçados com uma média de 15 minutos de diferença do início ao final do debate.

Com os tuites extraídos, foi utilizada a versão 0.9.2 do Gephi ${ }^{5}$, um software de exploração, processamento, visualização e análise de dados. Com o Gephi, é possível gerar uma rede dinâmica e hierárquica de nós, em que se pode aplicar diversos algoritmos para a visualização dos atores mais importantes e influentes, os temas mais utilizados, além da visualização de grupos compostos por nós que possuem uma maior conexão entre si.

Para a análise qualitativa, foram utilizados alguns recortes propostos para $\mathrm{o}$ estudo. Esses recortes se baseiam em três momentos específicos do debate que vieram a ser destaque entre os 10 mil tuites. São eles: (1) a pergunta do candidato Fernando Haddad ao candidato Guilherme Boulos após os primeiros 26 minutos de debate; (2) após 1 hora e 14 minutos de debate, a pergunta da candidata Marina Silva para o candidato Fernando Haddad; e (3) em 1 hora e 53 minutos de debate, a pergunta de Ciro Gomes para o candidato Henrique Meirelles.

Por fim, utilizou-se para a classificação da rede, as métricas Grau de Entrada (Indegree), que Recuero (2017, s/p) define como o "número de conexões que um determinado nó recebe", e Grau de Saída (Outdegree), descrito pela autora como o "número de conexões que um determinado nó faz", a fim de apontar os principais atores de acordo com cada métrica. Foi utilizada também a métrica Grau de Intermediação (Betweeness) que, para Recuero (2017, s/p), indica "o quanto um determinado ator conecta diferentes grupos", além do uso da Modularidade, que, segundo a autora, se relaciona "à tendência de determinados nós se conectarem entre si". Ainda, a análise envolveu temas mais abordados, as hashtags mais utilizadas e os atores mais citados.

\section{Coleta e Análise dos Dados}

O último debate dos presidenciáveis do primeiro turno das eleições brasileiras de 2018 ocorreu no dia 4 de Outubro de 2018, uma quinta-feira, três dias antes do dia da votação para o primeiro turno (domingo, dia 07 de outubro de 2018). Estavam presentes no debate os candidatos à presidência Alvaro Dias, Ciro Gomes, Fernando Haddad, Geraldo

5 Disponível em https://gephi.org/. 
Alckmin, Guilherme Boulos, Henrique Meirelles e Marina Silva. O então candidato Jair Bolsonaro foi convidado mas informou que não compareceria por recomendação médica ${ }^{6}$.

O debate foi transmitido pela TV Globo, com duração aproximada de 2 horas e 45 minutos, das $22 \mathrm{~h} 08$ às 00h54 (horário de Brasília). Durante esse período, utilizando-se do Netlytic, foram coletados ao todo 10.000 tuítes $^{7}$ contendo o termo \#DebateNaGlobo, publicados por 1043 usuários diferentes, sendo 6.641 retuítes identificados.

O grau de entrada (indegree) foi a métrica aplicada para identificar os atores que receberam mais atenção, menções e referências por outros usuários. Já o grau de intermediação (betweenness) foi considerado para identificar os atores que serviram de ponte para conectar à rede. No caso do grau de saída (outdegree), utilizou-se na identificação dos atores que estabeleceram mais conexões com outros usuários na rede.

O Quadro 1 lista os 10 usuários com maior número de conexões indegree, ou seja, mais obtiveram menções e/ou retuítes pelos outros usuários.

Quadro 1 - Atores com maior grau de entrada na rede

\begin{tabular}{|c|c|c|}
\hline$\#$ & Perfil & Grau \\
\hline 1 & cirogomes & 164 \\
\hline 2 & haddad_fernando & 153 \\
\hline 3 & guilhermeboulos & 142 \\
\hline 4 & jairbolsonaro & 75 \\
\hline 5 & alvarodias__ & 56 \\
\hline 6 & meirelles & 50 \\
\hline 7 & marinasilva & 43 \\
\hline 8 & aosfatos & 40 \\
\hline 9 & geraldoalckmin & 39 \\
\hline 10 & redeglobo & 29 \\
\hline
\end{tabular}

Fonte: Twitter (2018)

Dentre esses 10 perfis, é possível identificar que, em sua maioria, foram mais citados os candidatos à presidência. É importante ressaltar que o candidato Jair Bolsonaro, apesar de aparecer em primeiro nas pesquisas na época, teve seu perfil figurando apenas em quarto lugar entre os tuítes mais mencionados. Apenas dois perfis apresentados no

6 Disponível em: https://politica.estadao.com.br/noticias/eleicoes,por-orientacao-medica-bolsonaro-nao-participara-de-debate-na-tv-globo,70002530755. Acesso em: 12 dez 2018.

7 O dataset extraído e utilizado está disponível para consulta em: https://docs.google.com/spreadsheets/ d/16eNjvKtRSYaBN431OCYAe4OhIe4t6gt3rJ0hAqI7_0U/edit?usp=sharing. 
quadro são de veículos de comunicação. O @redeglobo pertence a emissora que veiculou o debate e o@aosfatos é o perfil de uma agência de checagem de notícias que verifica a veracidade em tempo real das afirmações feitas pelos candidatos durante o debate. $\mathrm{Na}$ sequência, a Figura 1 representa a rede desses dados agrupada pelo software Gephi:

Figura 1 - Grafo de Indegree da rede agrupado por modularidade

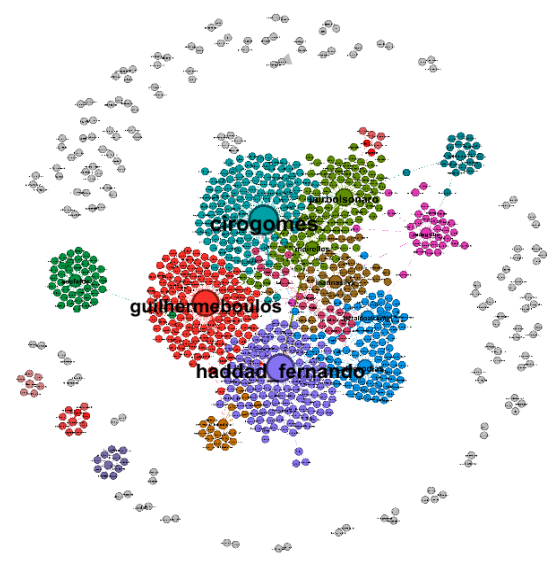

Fonte: Twitter (2018)

Aplicando-se o algoritmo de modularidade, foram identificados nove diferentes grupos com tamanho igual ou superior a 5\% do total de usuários (nós) da rede, ilustrados por cores distintas. Cada um desses grupos representa um conjunto de usuários aproximados por suas conexões, o que serve de base empírica para esta análise, por meio das cartografias das redes que a compõem. No Quadro 2 encontram-se as estatísticas gerais de cada um desses 9 grupos, de maior para menor tamanho:

Quadro 2 - Grupos separados por Modularidade

\begin{tabular}{|c|c|c|}
\hline \multicolumn{1}{|c|}{ Cor } & Conexões & Usuários proeminentes \\
\hline Azul-esverdeado & 164 & @cirogomes \\
\hline Roxo & 153 & @ haddad_fernando \\
\hline Vermelho & 142 & @guilhermeboulos \\
\hline Verde-musgo & 125 & @jairbolsonaro, @meirelles \\
\hline Azul Claro & 95 & @alvarodias_, @geraldoalckmin \\
\hline Marrom & 43 & @marinasilva \\
\hline Verde-claro & 40 & @redeglobo \\
\hline Rosa & 29 & @cabodaciolo \\
\hline Azul-Escuro & 19 & \\
\hline
\end{tabular}

Fonte: autores 
Como observado na Figura 1 e no Quadro 2, os usuários com maior número de conexões foram os candidatos à presidência Ciro Gomes, Fernando Haddad, Guilherme Boulos, Jair Bolsonaro, Henrique Meirelles, Geraldo Alckmin e Marina Silva. Apesar de não terem participado do debate, Jair Bolsonaro e Cabo Daciolo estão entre os mais citados. Jair Bolsonaro, por liderar as pesquisas para presidência na época, recebeu diversas críticas pelos outros presidenciáveis durante o debate por não ter comparecido ao encontro e também por apoiar medidas com alto grau de controversa. Já o candidato Cabo Daciolo aparece, na maior parte das vezes, citado de forma cômica por seu discurso estereotipado. A presença combinada dos perfis@jairbolsonaro e@meirelles em um mesmo grupo está relacionada ao fato de que os usuários realizaram diversos tuítes mencionando ambos atores, em suma, criticando o candidato Jair Bolsonaro, como mostram os exemplos abaixo:

RT@victohipolito: Nesse momento@meirelles compara@jairbolsonaro a Color e a possibilidade dele destruir novamente o Brasil e não ter governabilidade. @cirogomes responde de forma cirúrgica sobre esse problema e confronto \#Ciro12 \#TsunamiCIRO \#DebateNaGlobo.

RT@Poder360: @meirelles em resposta a @cirogomes sobre @jairbolsonaro: “O eleitor merece respeito. Se alguém foge do debate, se esconde e só vai dar entrevista em situação de absoluto controle, significa que essa pessoa não tem condições de administrar o país" \#DebateNaGlobo \#aovivoPoder360.

Outros dois perfis aparecem no mesmo grupo, que é o caso de @alvarodias_e (a)geraldoalckmin, ocorrendo o oposto do exemplo anterior. Os usuários mencionaram ambos atores por estarem apoiando um ao outro durante o debate.

RT@dirceuaurelio:@alvarodias_apoiando claramente@geraldoalckmin...fim da picada \#debatenaglobo.

RT@huffpostbrasil: \#DebateNaGlobo@geraldoalckmin e@alvarodias_disputam o voto do antipetismo: "Nós já tivemos a experiência do Pt e vimos o resultado disso", reforça o tucano. 
No Quadro 3, foram reservadas para análise as hashtags mais utilizadas entre os usuários durante o debate para, assim, verificar a força de um determinado tema ou objeto proposto durante a corrida eleitoral.

Quadro 3 - Hashtags mais utilizadas

\begin{tabular}{|c|c|}
\hline Hashtag & Mensagens \\
\hline \#tsunamiciro & 657 \\
\hline \#haddadé13 & 460 \\
\hline \#ciro12 & 446 \\
\hline \#boulosnaglobo & 435 \\
\hline \#eleições2018 & 311 \\
\hline \#cironaglobo & 243 \\
\hline \#cirosim & 233 \\
\hline \#bolsonaronarecord & 120 \\
\hline \#vote18 & 99 \\
\hline \#elenão & 71 \\
\hline
\end{tabular}

Fonte: Twitter (2018)

Entre as 10 hashtags mais utilizadas, 4 delas se mostram a favor do candidato Ciro Gomes (\#tsunamiciro, \#ciro12, \#cironaglobo, \#cirosim), o que demonstra a força que esse candidato possui na rede social. A \#haddadé13 aparece em segundo lugar como a mais citada, seguida da \#boulosnaglobo, a favor do candidato Guilherme Boulos. Essas hashtags somadas a \#vote18, a favor de Marina Silva, e \#elenão, dão um panorama do tamanho da rejeição ao candidato Jair Bolsonaro na rede social durante o debate, que emplacou somente a sétima hashtag mais utilizada: \#bolsonaronarecord, devido ao fato de que a emissora Rede Record transmitiu uma entrevista com o mesmo durante os primeiros 30 minutos de debate.

No Quadro 4 foram separadas as palavras mais utilizadas nas frases dos usuários, sem contar com hashtags ou nomes de candidatos, para introdução da próxima seção proposta neste estudo, assim, entendendo como a rede se comportou após os acontecimentos ocorridos durante o debate. 
Quadro 4 - Termos mais utilizados nas frases

\begin{tabular}{|c|c|}
\hline Termo & Mensagens \\
\hline Debate & 1299 \\
\hline Brasil & 640 \\
\hline candidato & 573 \\
\hline ditadura & 509 \\
\hline amarelou & 429 \\
\hline entrevista & 428 \\
\hline record & 383 \\
\hline pergunta & 372 \\
\hline país & 345 \\
\hline nunca & 298 \\
\hline
\end{tabular}

Fonte: Twitter (2018)

Neste quadro pode-se visualizar algumas palavras-chave determinantes para essa análise; são elas "ditadura", "amarelou" e também o termo "fraquejada" que, apesar de não estar entre as mais faladas na amostra, foi destaque após 1 hora e 50 minutos de debate, obtendo 77 menções em menos de 30 segundos de coleta.

Observa-se na Figura 2 que o grafo de Outdegree é bem diferente do grafo de Indegree. Os nós em destaque já não mais são os atores mais mencionados e sim os que mais fizeram menções a outros usuários da rede.

Figura 2 - Grafo de Outdegree da rede agrupado por modularidade

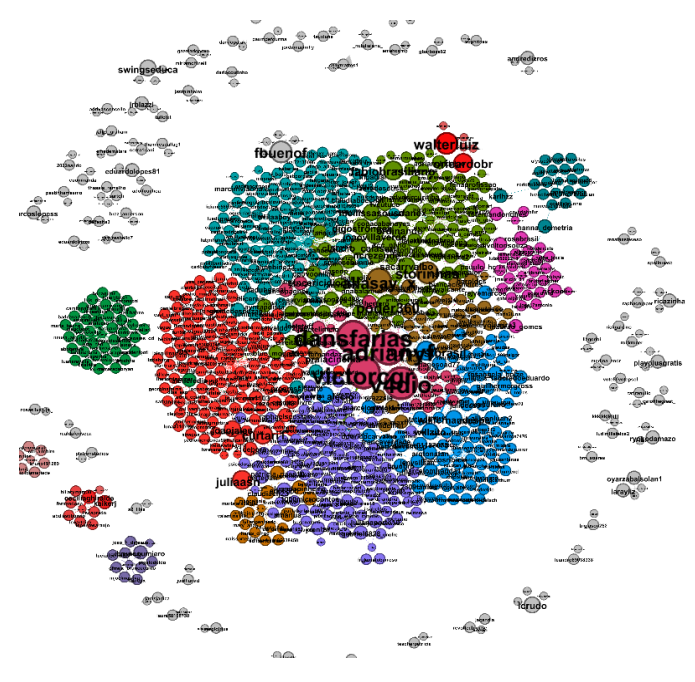

Fonte: Twitter (2018) 
Destacam se na rede por grau de saída os atores@adrianyf,@dansfarias,@v4dio, @victorcgr,@allasay_x,@walterluiz,@poder360, entre outros. São esses os usuários que mais fizeram menções a outros usuários e/ou retuítaram outros usuários dentro dessa amostra.

Os atores@adrianyf,@dansfarias,@v4dio e@victorcgr se destacam bem ao centro da rede por retuítarem um post de um grande canal de imprensa on-line, o Vice Brasil, mencionando ao todo 9 atores dentro da rede, como mostra o tweet abaixo feito por@adrianyf:

RT@VICEBRASIL:@meirelles@cirogomes@GuilhermeBoulos@Haddad_Fernando @alvarodias_@geraldoalckmin@MarinaSilva@KatiaAbreu@realwbonner O@ cirogomes chama@meirelles para chamar Bolsonaro de mentiroso. Bate na questão do $13^{\circ}$, lembra que foi ao debate logo após uma cirurgia enquanto Bolsonaro fugiu do debate mas deu entrevista, e criticou a falta de preparo da equipe do ex-capitão. \#debatenaglobo https://t.co/sDQmzsKXcp.

Entre esses quatro atores, destaca-se o @dansfarias, pois além de ter retweetado este post da Vice Brasil, também retweetou um post do Buzz Feed Brasil, outro portal de notícias famoso no país:

RT@BuzzFeedBrasil: Faça como o Ciro, pessoal: BEBA ÁGUA \#DebateNaGlobo.

Já entre os demais destacados, o nó de @poder360, um portal on-line sobre matérias políticas que transmitia via Twitter o debate em tempo real, foi o que obteve um maior número de tuítes coletados em momentos diferentes do debate. Ao todo, o @ poder360 apresenta 3 tuítes mencionando 7 outros atores:

@meirelles em resposta a @ cirogomes sobre@jairbolsonaro: “O eleitor merece respeito. Se alguém foge do debate, se esconde e só vai dar entrevista em situação de absoluto controle, significa que essa pessoa não tem condições de administrar o país" \#DebateNaGlobo \#aovivoPoder360.

@Haddad_Fernando a @cirogomes: "Não precisamos derrubar árvores, precisamos combater a especulação das terras. Precisamos atualizar a tabela da terra improdutiva, apesar da pressão dos ruralistas arcaicos”. \#DebateNaGlobo \#aovivoPoder360. 
@MarinaSilva diz que fará pergunta a @Haddad_Fernando que queria fazer à @ jairbolsonaro. "Como ele mais uma vez amarelou, deu uma entrevista à Record, mas não quis estar aqui conosco". \#DebateNaGlobo \#aovivoPoder360.

Analisando o grafo de intermediação (betweenness) na Figura 3, pode-se observar que são poucos os atores que fazem o papel de "influenciadores" da rede. Os atores destacados nesse grafo são o @rede45, perfil no Twitter do partido PSDB, do candidato Geraldo Alckmin, e também o usuário@wesleyoliveira3.

Figura 3 - Grafo de Intermediação agrupado por modularidade

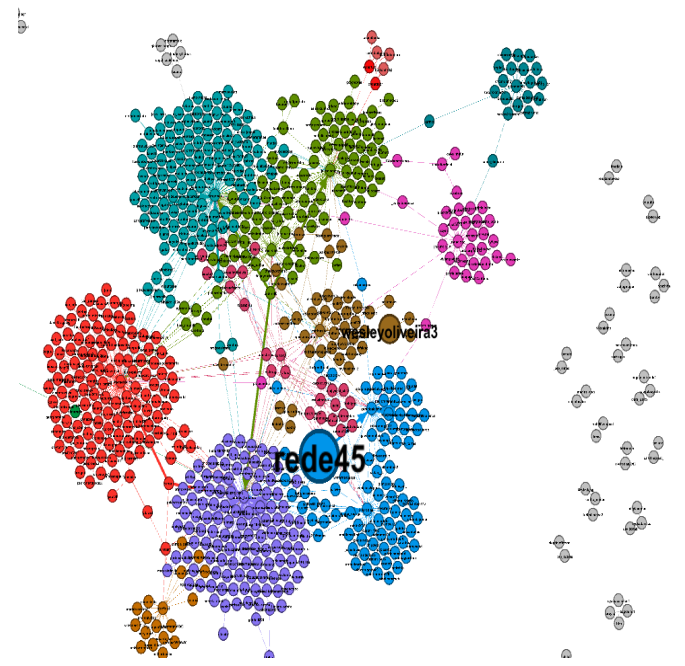

Fonte: Twitter (2018)

O perfil@rede45 se destaca por além de ter retweetado posts de perfis que faziam parte de outros grupos, teve seus próprios tuítes compartilhados por atores de outros agrupamentos também. Abaixo um retweet deste perfil compartilhado de um ator de outro grupo:

RT@g_mustafa: O Brasil não pode deixar passar a oportunidade de ter @geraldoalckmin Presidente. Uma vida de dedicação, responsabilidade e RESULTADO!! SP superavitário em meio a enorme crise nacional, salários em dia, remédio mais barato, combustível mais barato. \#DebateNaGlobo \#Geraldo45 BRBR. 
Dentre os tuítes do ator@rede45, constatou-se na amostra 7 retuítes postados por diversos atores da rede. Segue abaixo um exemplo desses tuítes, que foi compartilhado por 2 atores:

RT@rede45: Enquanto o Brasil passou pela mais grave crise econômica das últimas décadas,@geraldoalckmin manteve as contas de São Paulo em dia e ainda reduziu impostos de remédios e do etanol, além de zerar o ICMS de alimentos básicos como pão e macarrão! \#DebateNaGlobo \#Geraldo45 \#Vote45 https://t.co/LYHTe4ZdCx.

Já o perfil@wesleyoliveira3 também foi responsável por esse "repasse" de tuítes entre grupos. Abaixo um exemplo de retweet coletado do ator:

RT@folha: A candidata Marina Silva arrancou aplausos da plateia após dizer que Jair Bolsonaro (PSL) 'amarelou' ao se ausentar o debate da TV Globo; siga https://t. co/4XoIsPxPN4 \#Eleições2018 \#DebateNaGlobo https://t.co/pX1gtGnpCw.

Apesar de ter apenas um tweet seu compartilhado por um ator de um grupo diferente, o perfil@maria2luna mencionou@wesleyoliveira3 em um tweet seu, como mostra abaixo:

@wesleyoliveira3 \#DebateNaGlobo \#ViraMarina18.

Em resumo, foram destacados os grupos por modularidade, ou seja, por proximidade da rede, identificados os atores com maior participação na rede, as hashtags mais utilizadas pelos atores da rede, os termos também mais utilizados nos tuítes, os atores destacados pelo grau de entrada (Indegree) e os atores destacados por grau de saída (Outdegree), bem como os atores destacados por grau de intermediação (betweenness).

\section{Análise da Rede após a Pergunta de Fernando Haddad a Guilherme Boulos aos 26 Minutos de Debate}

Questionado por Fernando Haddad sobre sua avaliação das declarações feitas pela equipe do candidato Jair Bolsonaro, a exemplo da crítica do candidato a vice-presidente da chapa Hamilton Mourão ao $13^{\circ}$ salário, Guilherme Boulos utilizou seu tempo para fazer um apelo, alertando sobre o risco de retorno ao regime militar. 
Figura 4 - Pergunta de Fernando Haddad a Guilherme Boulos

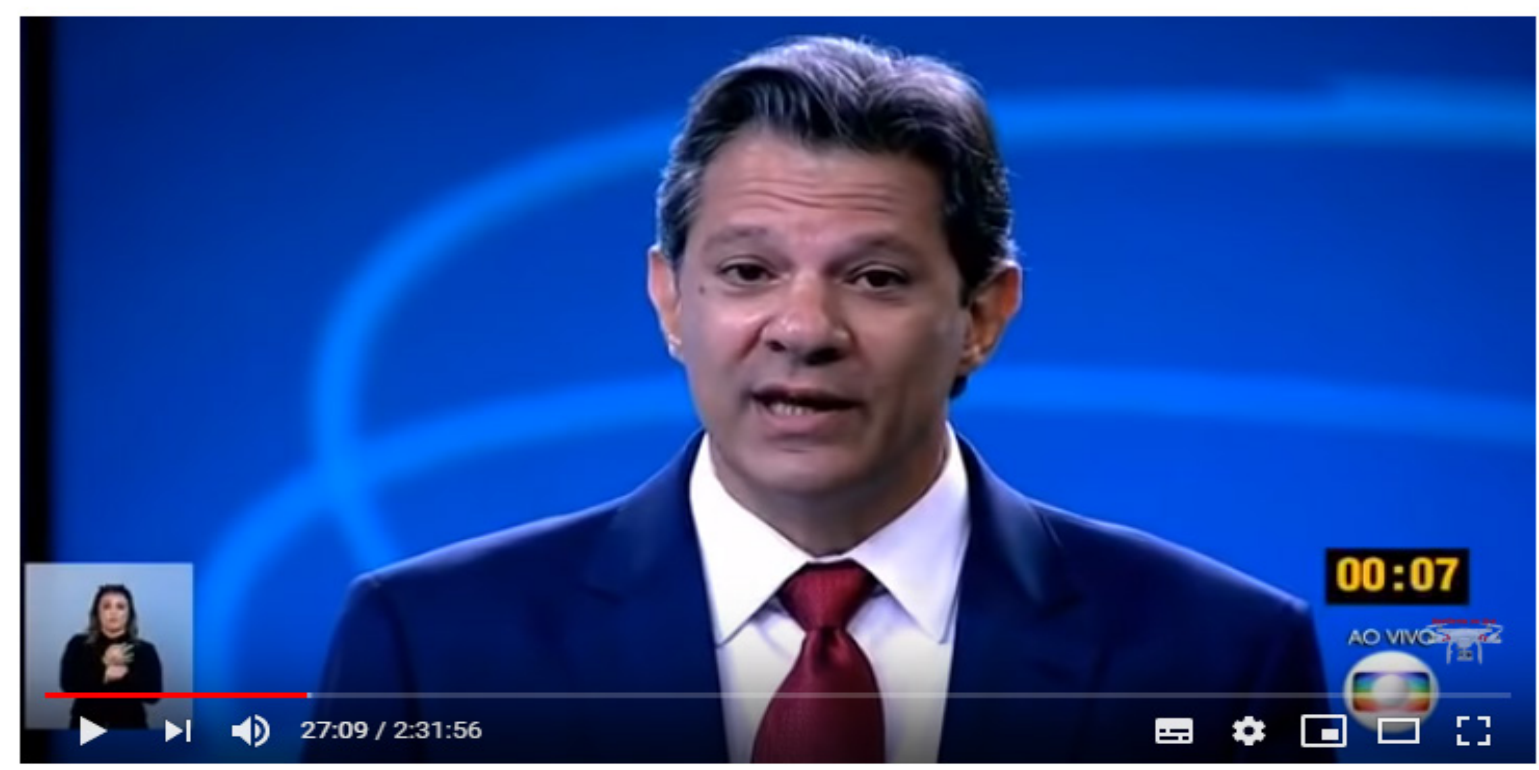

\#Compartilhe \#Haddad13 \#DebateGlobo

Último debate dos presidenciáveis 2018 na Globo

Fonte: YouTube (2018)

Respondeu o candidato Boulos:

Não dá para a gente fingir que está tudo bem. O momento é grave. Estamos há meses em uma campanha marcada pelo ódio. Faz 30 anos que esse país saiu de uma ditadura. Muita gente morreu, muita gente foi torturada. Tem mãe que não conseguiu enterrar o filho até hoje. Faz 30 anos mas acho que nunca estivemos tão perto. Se estamos hoje discutindo o futuro do brasil é porque gente derramou sangue para isso. Quando eu nasci o Brasil estava numa ditadura. Não quero que minhas filhas cresçam numa ditadura. Sempre começa assim. Acho que a gente tem que dar um grito, um basta: ditadura nunca mais.

Enquanto Fernando Haddad fazia sua réplica, alguns usuários já começaram a enaltecer a resposta do candidato Boulos na rede. Segue um retweet do ator@luiixxH, feito às 23h02, de um tweet do usuário @alissonnobrien, o qual retweetava um vídeo de um outro ator não coletado pela nossa amostra.

RT@alissonnobrien: q discurso esse do boulos brasil q discurso! \#DebateNaGlobo https://t.co/i3SO6FVdXs. 
Para que se tenha uma visão melhor da dimensão de toda a rede, o vídeo, presente na URL do retweet acima, foi postado pela primeira vez pelo perfil @limaalef, obtendo 3.984 retuítes, 10.353 likes e mais de 971 mil visualizações. Segue outro retweet sobre a resposta de Guilherme Boulos ao Fernando Haddad feito pelo usuário @labbeax:

RT@tlmota: a fala histórica do boulos contra a ditadura. pra rever e se emocionar de novo \#DebateNaGlobo. https://t.co/jsJRjjhKIi.

O perfil@tlmota, por sua vez, replicava um vídeo do perfil@MidiaNinja, pertencente a um grupo ativista, postado às $22 \mathrm{~h} 46$, logo após o momento da fala de Boulos. É importante ressaltar que, como mostram a Figura 5 e a Figura 6, o post original recebeu 1.860 retuítes e 4.537 likes, enquanto o retweet feito por@tlmota obteve 11.739 retuítes e 27.010 likes. Ou seja, um usuário comum ampliou em, pelo menos, cerca de 6 vezes o alcance de um vídeo postado por um grupo ativista.

Figura 5 - Postagem original feita por@MidiaNinja

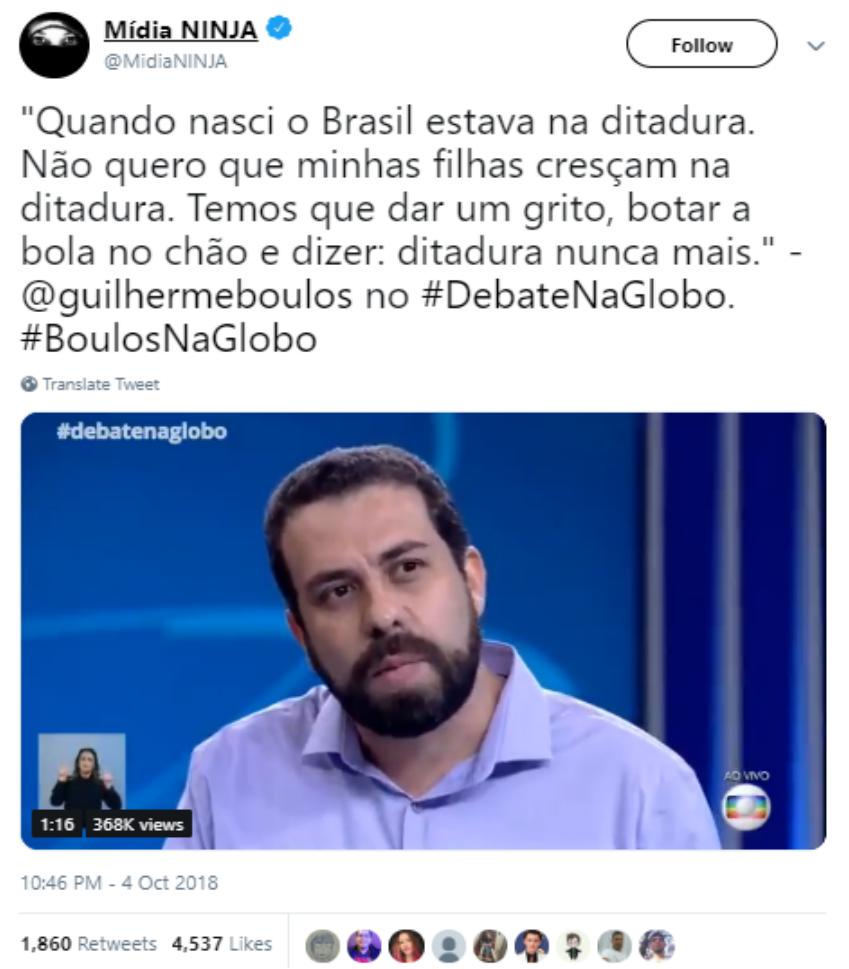

Fonte: Twitter (2018) 
Figura 6 - Repostagem do vídeo de @MidiaNinja por@tlmota

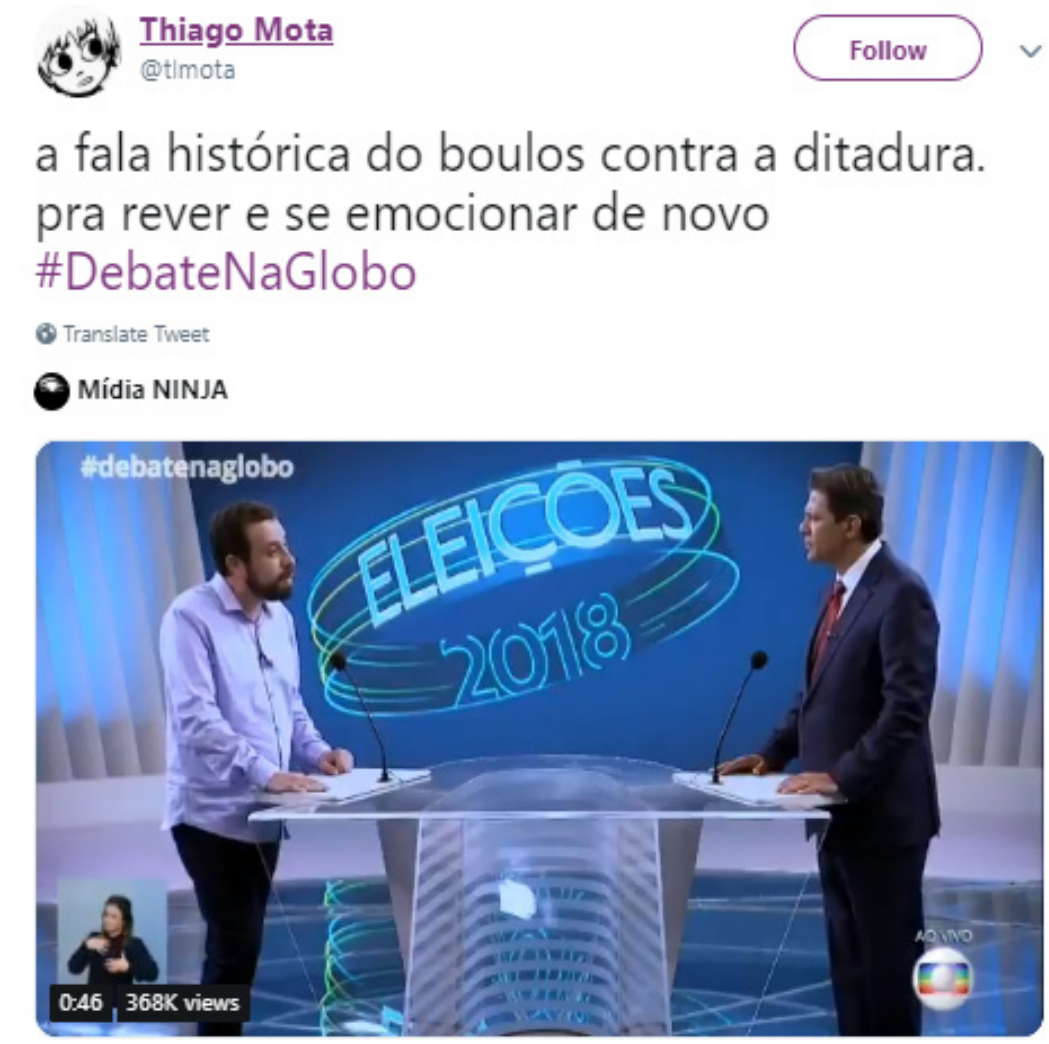

10:53 PM - 4 Oct 2018

11,739 Retweets 27,010 Likes

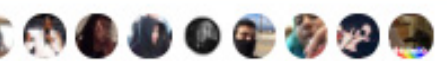

Fonte: Twitter (2018)

A repercussão dessa resposta de Boulos foi notável durante toda a coleta de dados no período do debate. Além do termo "ditadura", usado pelo mesmo, tendo se tornado o $4^{\mathrm{o}}$ termo mais utilizado na coleta, conforme apontado no Quadro 4, alguns usuários ainda comentavam sobre a mesma até o fim do debate, como mostra o retweet feito às $00 \mathrm{~h} 22$, cerca de 1h40 minutos depois, pelo perfil@Tereza47:

RT @elpais_brasil: \ $\square$ No \#DebateNaGlobo Haddad (PT) pergunta a Guilherme Boulos (PSOL) sobre sua opinião a respeito das declarações da campanha de Bolsonaro (PSL) a respeito da eliminação do $13^{\circ}$ salário e outros direitos trabalhistas \#Eleicoes2018. https://t.co/NyjFFM9iK4. 
Apesar do perfil@elpais_brasil ser o representante brasileiro no Twitter de um grande jornal espanhol, possuindo neste perfil mais de 360 mil seguidores, essa sua postagem obteve apenas 66 retuítes e 309 likes, como mostra a Figura 7.

Figura 7 - Tweet feito por @elpais_brasil sobre a resposta de Boulos a Haddad

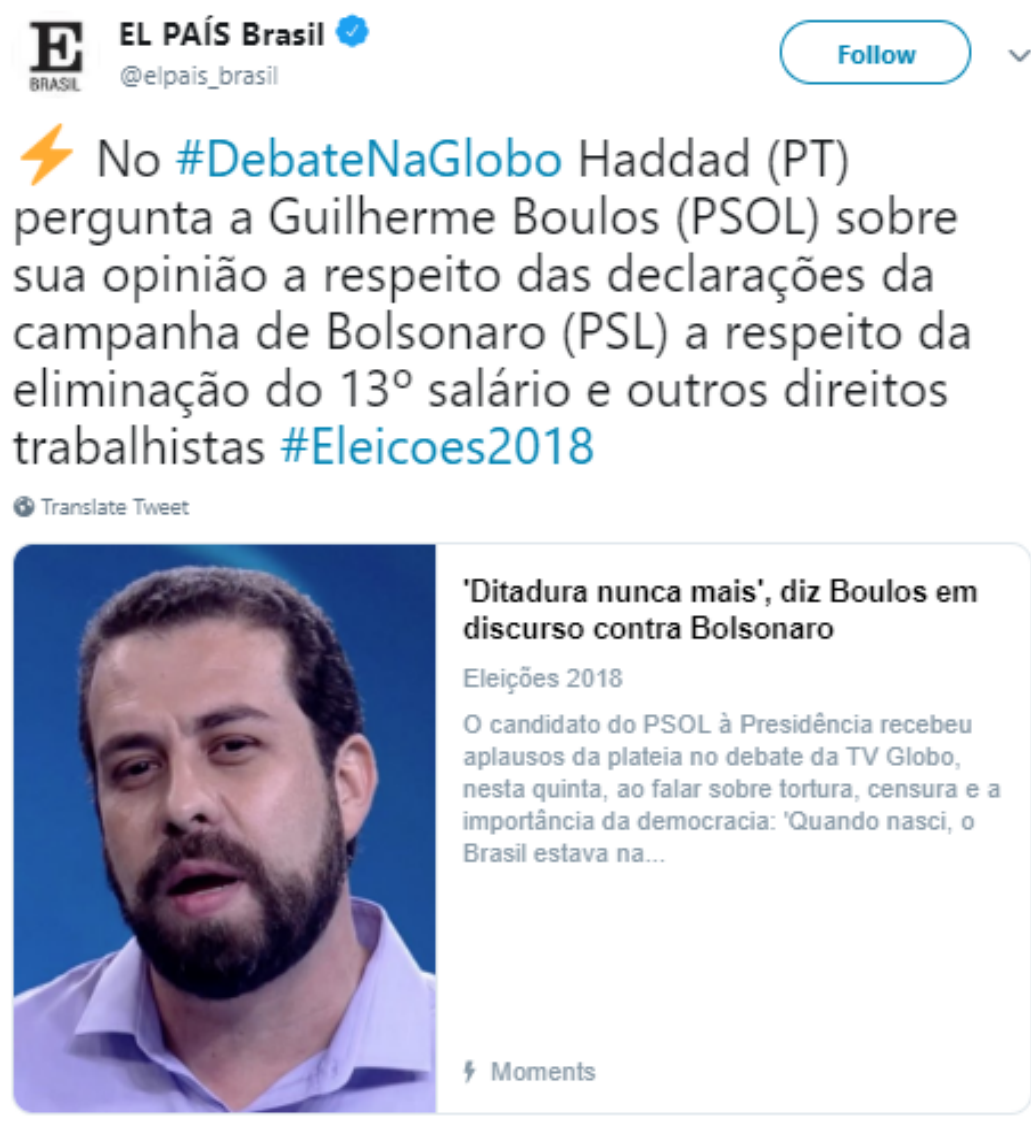

$12: 00 \mathrm{AM}-5$ Oct 2018

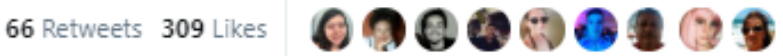

Fonte: Twitter (2018)

\section{Análise da Rede após a Pergunta de Marina Silva a Fernando Haddad a 1 Hora e 14 Minutos de Debate}

A candidata Marina Silva, ao introduzir sua pergunta ao candidato Fernando Haddad, disse: "Eu iria fazer essa pergunta também para o candidato Bolsonaro, que mais uma vez amarelou, deu uma entrevista na Record, e não está aqui debatendo conosco. E a pergunta é: Nós temos um país...”. 
Figura 8 - Pergunta de Marina Silva a Fernando Haddad

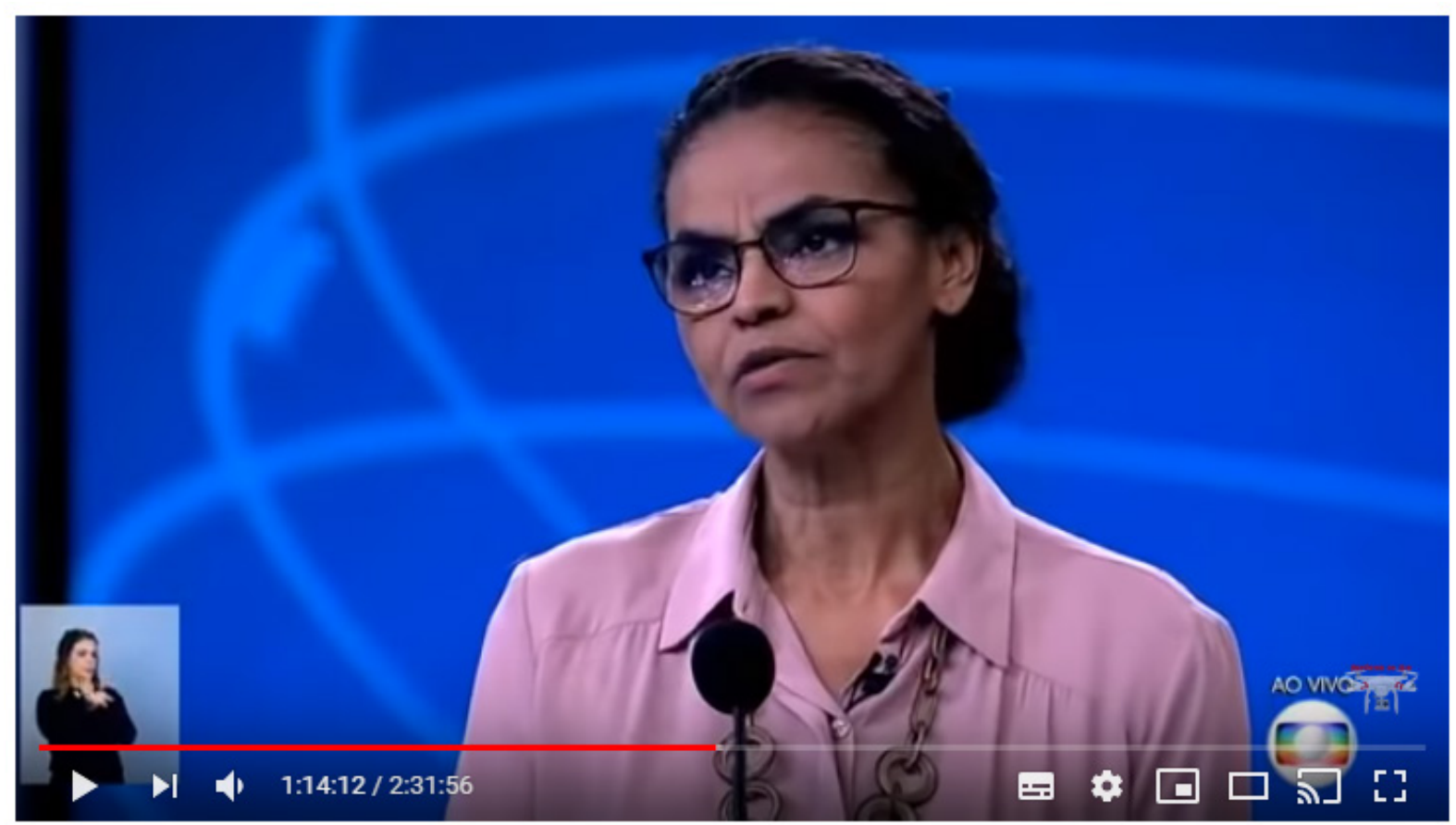

\#Compartillhe \#Haddad13 \#DebateGlobo

Último debate dos presidenciáveis 2018 na Globo

Fonte: YouTube (2018)

Nesse momento, ao ser aplaudida pela plateia, Marina Silva foi interrompida pelo mediador do debate, o jornalista William Bonner, que pediu para o público não se manifestar. Isso bastou para que um dos termos utilizados por Marina se tornasse um dos mais repetidos pela rede social. A palavra "amarelou", como demonstra o Quadro 4, foi um dos termos mais repetidos pelos atores da rede, sendo utilizado inclusive para criação de charges cômicas em críticas ao candidato Jair Bolsonaro, que não participou do debate. Somente na amostra levantada, há a presença de 100 retuítes, que ocorreram entre os horários $23 \mathrm{~h} 27$ e 00h21, do post do perfil @RealitySocial, que logo após a pergunta tweetou:

Eu ia fazer essa pergunta para o Bolsonaro que mais uma vez amarelou, deu uma entrevista para a Record e não veio debater conosco. \#DebateNaGlobo https://t.co/imEeNnziAH.

Esta postagem obteve 2.986 retuítes ao todo e 5.866 likes, como mostra a Figura 9: 
Figura 9 - Tweet feito por @RealitySocial sobre a pergunta de Marina a Haddad

(B) Reality Social $\theta$

@RealitySocial

"Eu ia fazer essa pergunta para o Bolsonaro

que mais uma vez amarelou, deu uma entrevista para a Record e não veio debater conosco." \#DebateNaGlobo

6 Translate Tweet

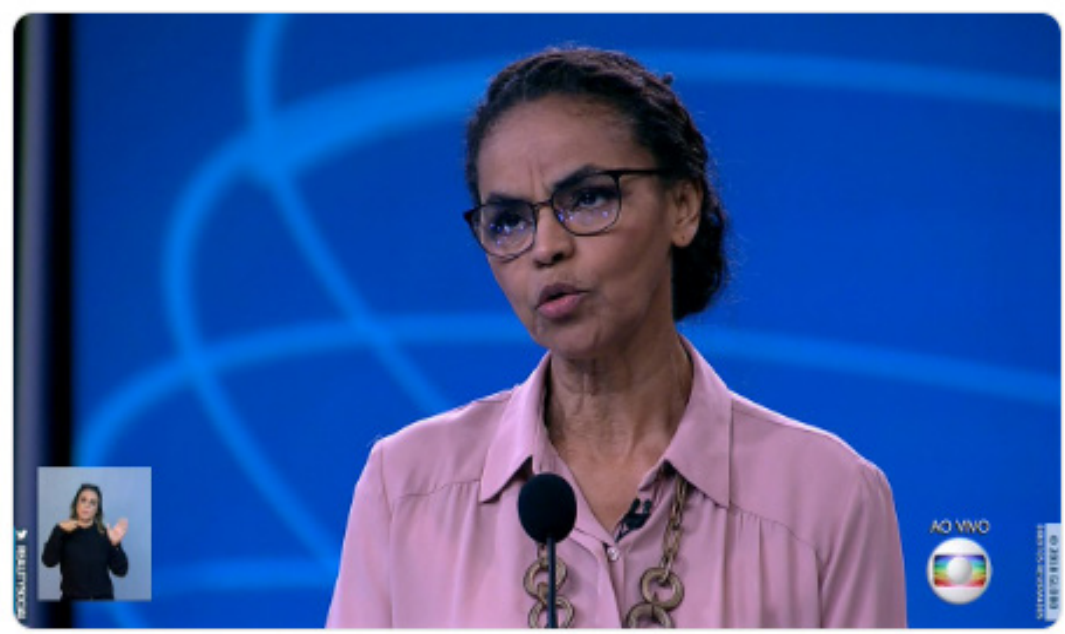

11:26 PM - 4 Oct 2018

2,986 Retweets 5,868 Likes
Follow

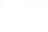


Figura 10 - Tweet feito por@JoelAlexandreM sobre a pergunta de Marina a Haddad

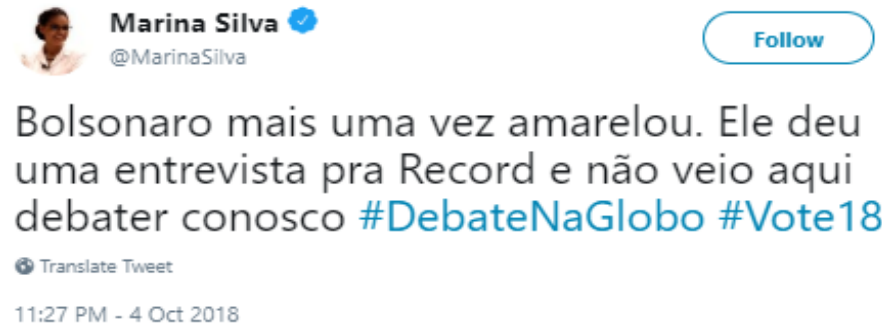

11:27 PM - 4 Oct 2018

3.715 Retweets 15,019 Likes 200 (3)

Fonte: Twitter (2018)

Porém, pode-se observar no banco de dados coletado, que, em sua maioria, as respostas dos usuários na amostra foram de apoio a candidata Marina Silva. O próprio Twitter da candidata, como aponta a Figura 11, obteve 3.715 retuítes e 15.019 likes, o que demonstra, mais uma vez, o tamanho da rejeição ao candidato Jair Bolsonaro, na rede, durante o debate.

Figura 11 - Tweet feito por @MarinaSilva sobre a pergunta de Marina a Haddad

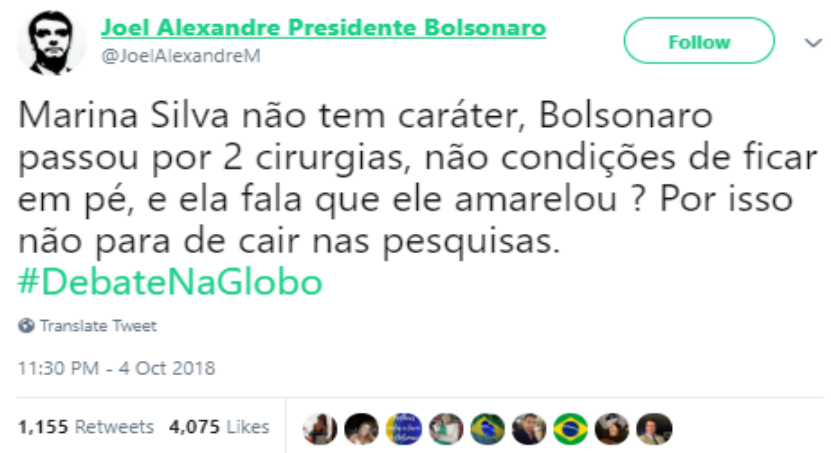

Fonte: Twitter (2018)

\section{Análise da Rede após a Pergunta de Ciro Gomes a Henrique Meirelles a 1 Hora e 56 Minutos de Debate}

O candidato Ciro Gomes, ao realizar uma pergunta ao candidato Henrique Meirelles, conforme Figura 12, fez uma clara menção a uma declaração dada pelo candidato Jair Bolsonaro em setembro de 2017, proferida na sede do Clube Hebraica da cidade do Rio de Janeiro. Na ocasião, o ainda deputado Jair Bolsonaro comentou: "Eu 
tenho cinco filhos. Foram quatro homens, aí no quinto eu dei uma fraquejada e veio uma mulher", sob risos da maior parte dos espectadores.

Figura 12 - Pergunta de Ciro Gomes ao candidato Henrique Meirelles

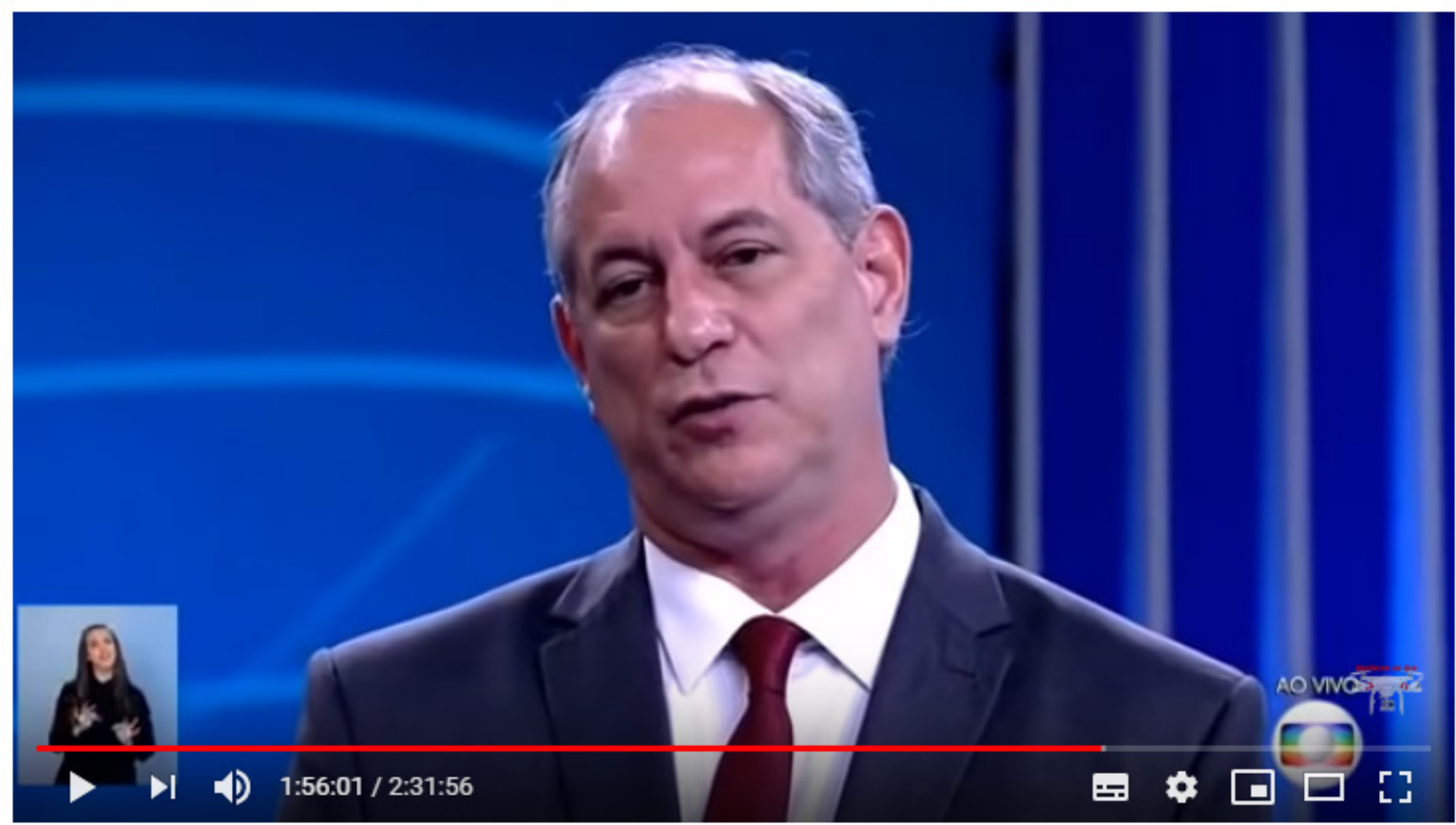

\#Compartilhe \#Haddad13 \#DebateGlobo

Último debate dos presidenciáveis 2018 na Globo

Fonte: YouTube (2018)

Essa declaração foi relembrada na pergunta de Ciro: "Eu tenho uma filha e uma neta que são o meu orgulho, e que não foram resultado de nenhuma fraquejada, são o meu orgulho, razão da minha alegria”. Como essa declaração foi uma das últimas perguntas do debate, não foi possível coletar mais tuítes após seu término. Porém, a partir da base de dados, foi possível ter uma dimensão da repercussão causada por esse comentário de Ciro. Em apenas 30 segundos, foram realizadas 77 menções ao termo "fraquejada" logo após a pergunta do candidato. Ao analisar alguns tuítes, constatou-se a repercussão na rede do comentário do candidato. Abaixo alguns retuítes que foram replicados por diversos usuários apenas durante esses 30 segundos:

RT@bchartsnet: “Tenho orgulho da minha filha, que não foi resultado de uma fraquejada" O MASSACRE DO CIRO NÃO PARANO@\#DebateNaGlobo. 
RT@Itspedrito: “Tenho uma filha e uma neta que são meu orgulho e não resultado de uma fraquejada”. \#DebateNaGlobo https://t.co/X2GP9PyzBY.

RT@pandlernews: "Eu tenho uma filha e uma neta que eu amo muito e com certeza não foi resultado de nenhuma fraquejada". - Ciro Gomes, 2018 \#DebateNaGlobo https://t.co/dWxRcQCaFi.

Além de usuários, alguns perfis de veículos de comunicação também replicaram a fala do candidato Ciro Gomes, como demonstram as figuras 13, 14 e 15.

Figura 13 - Tweet do perfil @BuzzfeedNewsBr sobre o comentário de Ciro

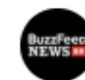

BuzzFeedNewsBR

@BuzzFeedNewsBR

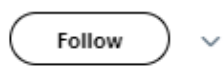

"Eu tenho uma filha e uma neta que são meu orgulho, não são resultado de nenhuma fraquejada", diz @cirogomes a @Meirelles. É uma referência a Bolsonaro ter dito, em uma entrevista, que só teve filhos homens até ter uma "fraquejada" e nascer uma menina. \#DebateNaGlobo

6) Translate Tweet

12:10 AM - 5 Oct 2018

551 Retweets 1,832 Likes

(3) 300 9000

Fonte: Twitter (2018)

Figura 14 - Tweet do perfil @Destak sobre o comentário de Ciro

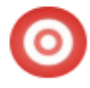

Jornal Destak

@destak

Follow

"Eu tenho uma filha e uma neta que são meu orgulho e não foram resultado de uma fraquejada", diz Ciro Gomes, em crítica a declaração de @jairbolsonaro feita no ano passado, onde o militar disse que só teve uma filha mulher por causa de uma" fraquejada". \#DebatenaGlobo

๑) Translate Tweet

12:11 AM - 5 Oct 2018

197 Retweets 560 Likes 구울우웅

Fonte: Twitter (2018) 
Figura 15 - Tweet do perfil @ catracalivre sobre o comentário de Ciro

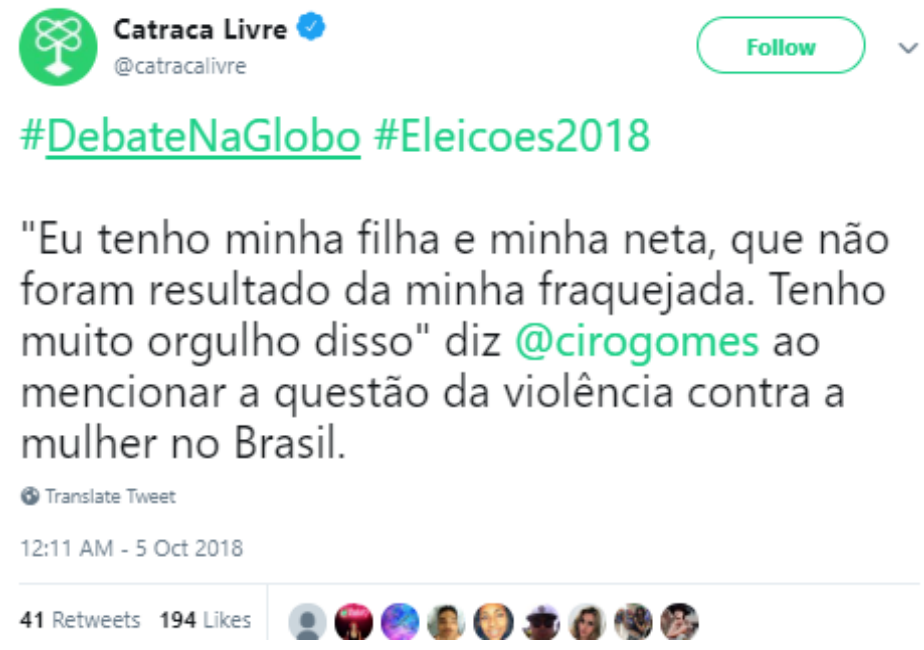

Fonte: Twitter (2018)

Vale ressaltar que juntos, esses três perfis de veículos de comunicação possuem mais de 2 milhões de seguidores e mesmo assim, seus tuítes sobre o ocorrido não surtiram o mesmo efeito que o tweet feito pelo usuário@itspedrito, que com 900 mil seguidores, obteve o dobro de retuítes com sua postagem de maneira cômica, conforme Figura 16.

Figura 16 - Tweet do perfil @itspedrito sobre o comentário de Ciro

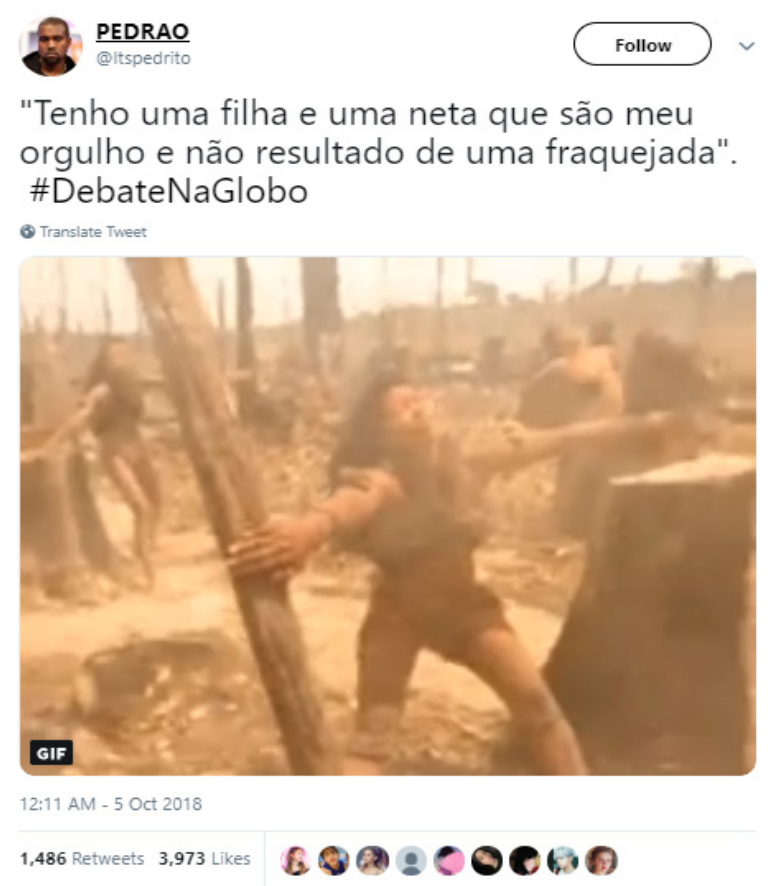

Fonte: Twitter (2018) 


\section{Considerações Finais}

Este trabalho buscou identificar os papéis dos usuários do site da rede social Twitter na disseminação de informações políticas a partir do estudo de um caso específico. $\mathrm{O}$ recorte utilizado se refere ao debate eleitoral entre os candidatos à Presidência da República do Brasil de 2018.

Em termos gerais, a análise apontou para a existência de dois papéis principais complementares: produtores e recirculadores de informação. Enquanto os perfis de veículos de imprensa e perfis de grupos ativistas são essenciais na produção de conteúdos, usuários comuns são fundamentais ao promover um maior alcance das informações, espalhando pelos agrupamentos da rede determinados desdobramentos em detrimento de outros.

No recorte analisado pela amostra, há uma hegemonia de replicações de tuítes feitos por veículos de imprensa, o que demonstra a relevância desses usuários como produtores de conteúdo, no caso de acontecimentos específicos. Da mesma maneira, a ação de usuários comuns ao retuitarem para suas redes tais conteúdos, denota a importância desses atores no sentido de disseminar a informação para usuários que anteriormente não tinham conexões com esses conteúdos, tornando-os, deste modo, os principais influenciadores da rede, por levarem as informações a pontos distantes dentro da rede.

Vale ressaltar que, pelo fato de os recirculadores poderem se utilizar de diferentes tipos de recursos linguísticos em suas mensagens, como a comédia, a crítica, adicionando emoção ao texto, suas mensagens, mesmo que retuitadas de veículos jornalísticos ditos imparciais, são mais bem recebidas por determinados grupos dentro da rede, o que pode fazer essa mensagem ter mais força dentro da rede do que aquela divulgada pelos produtores iniciais, como demonstra a análise deste trabalho. Dessa forma, usuários comuns possuem o poder de influenciar suas redes sociais, de maneira que o entendimento de um acontecimento, notícia ou tema seja distorcido ou visto de uma forma emotiva pelos outros usuários da rede, enviesando assim o intuito inicial dos veículos produtores de conteúdo.

Por fim, cabe destacar que a amostra coletada possui limitações em termos de abrangência, uma vez que o web crawler utilizado para a coleta dos tuítes limita-se a quantidade de 10.000, o que impossibilita analisar a rede da forma como ela realmente é. De qualquer modo, estudos futuros, com a aplicação da Análise de Redes Sociais em outros temas ou discussões, podem determinar uma variação nos papéis dos principais atores envolvidos, esclarecendo outros fatores não alcançados por essa pesquisa. 


\section{Referências}

ANGELUCI, A. C. B. TV, segunda tela e o ecossistema de engajamento. Interin (UTP), v. 19, p. 24-39, 2015.

ANTOUN, Henrique; FALCÃO, Paula. As jornadas de junho de 2013: O \#vemprarua no Brasil.

Esferas, Ano 4, no 7, jul/dez. 2015.

BARRIGA, Antónia do Carmo. O debate político nas "contra-esferas públicas": como se discute em 140 caracteres. Media \& Jornalismo, 25(14), pp. 111 - 126, 2015.

BARRIGA, Antónia do Carmo. Sobre a ausência de pluralismo nos média: como observar a invisibilidade do debate político nos novos média? In: MOREIRA, Ana; ARAÚJO, Emília; SOUSA, Helena (Eds.). Comunicação e Política: tempos, contextos e desafios. Braga: CECS, 2017. pp. 21-43.

BENEVENUTO, Fabrício; ALMEIDA, Jussara M.; SILVA, Altigran S. Explorando redes sociais online: da coleta e análise de grandes bases de dados às aplicações. Mini-cursos do Simpósio Brasileiro de Redes de Computadores (SBRC), 2011. Disponível em: https://homepages.dcc. ufmg.br/ fabricio/download/mini-curso-sbrc11.pdf. Acesso em: 3 nov. 2018.

BRUNS, Axel; BURGESS, Jean. Researching news discussion on Twitter: new methodologies. Journalism Studies, v. 13, ed. 5-6, p. 801-814, 22 mar. 2012.

BURT, Ronald S. Structural holes: the social structure of competition. Cambridge: Oxford University Press, 1992.

CAMPOS-DOMÍNGUEZ, Eva. "Twitter y la comunicación política”. El profesional de la información, v. 26, n. 5, pp. 785-793, 2017.

DUARTE, Jorge; RIVOIRE, Valéria; RIBEIRO, Ângelo Augusto. Mídias sociais online e prática jornalística: um estudo em Santa Catarina. Universitas: Arquitetura e Comunicação Social, v. 13, n. 1, p. 1-10, jan./jun. 2016.

RECUERO, Raquel. Introdução à análise de redes sociais online. Salvador, BA: EDUFBA. 2017. Disponível em: https://repositorio.ufba.br/ri/handle/ri/24759. Acesso em: 20 out. 2018.

RECUERO, Raquel. Redes sociais na internet. Porto Alegre: Sulina, 2009. 
RECUERO, Raquel; BASTOS; Marco Toledo; ZAGO, Gabriela. Análise de redes para mídia social. Porto Alegre: Sulina, 2015.

RECUERO, Raquel; ZAGO, Gabriela; SOARES, Felipe Bonow. Midia social e filtrosbolha nas conversações políticas no Twitter. In: Compós 2017. Anais [...], São Paulo, 2017. Disponível em: http://www.compos.org.br/data/arquivos_2017/trabalhos_arquivo_ XH5ITTDY1PYGE7PDUQJM_26_5374_18_02_2017_12_53_33.pdf $>$. Acesso em: 18 abr. 2019.

ROSSETTO, Graça; CARREIRO, Rodrigo; ALMADA, Maria Paula. Twitter e comunicação política: limites e possibilidades. Compolítica, v. 3, n. 2, p. 189-216, 22 dez. 2013.

SANTOS, Valmaria Lemos da Costa; SANTOS, José Erimar dos. As redes sociais digitais e sua influência na sociedade e educação contemporâneas. Holos, v. 6, p. 307-328, 2014.

ZAGO, Gabriela da Silva; BASTOS, Marco Toledo. Visibilidade de notícias no Twitter e no Facebook: análise comparativa das notícias mais repercutidas na Europa e nas Américas. Brazilian Journalism Research, v. 9, n. 1, p. 98-115, 2013.

ZAGO, Gabriela. Papéis dos usuários na circulação jornalística em sites de rede social: os atentados de Paris no Twitter. Estudos em Comunicação, n. 23, p. 23-43, dez. 2016.

ZENHA, Luciana. Redes sociais online: o que são as redes sociais e como se organizam? Caderno de Educação, n. 49, v. 1, p. 19-42, 2017/2018.

1 Professor Doutor do Programa de Pós-Graduação em Comunicação da Universidade Municipal de São Caetano do Sul (USCS), São Caetano do Sul - SP, Brasil. E-mail: aangeluci@prof.uscs.edu.br.

Professor permanente no Programa de Pós-Graduação em Comunicação (PPGCOM), Educação (PPGE) e na Graduação em Comunicação Social na Universidade Municipal de São Caetano do Sul (USCS). Desenvolveu estudos de pós-doutorado no Department of Radio-Television-Film, Moody College of Communication, University of Texas at Austin (EUA) e no Departamento de Informação e Cultura da Escola de Comunicações e Artes (ECA-USP). Doutor em Ciências com ênfase em Sistemas Eletrônicos pela Escola Politécnica da Universidade de São Paulo - EPUSP. Realizou Doutorado Sanduíche na University of Brighton, Inglaterra, por meio do programa Ciência sem Fronteiras (CNPq). Mestre em Televisão Digital pela Faculdade de Arquitetura, Artes e Comunicação da Universidade Estadual Paulista Júlio de Mesquita Filho - UNESP. Bacharel em Comunicação Social - Habilitação em Jornalismo pela mesma Instituição. É líder do Smart Media \& Users, cadastrado no diretório de grupos de pesquisas do CNPq. É coordenador do GP Conteúdos Digitais e Convergências Tecnológicas da Intercom.

2 Mestre pelo Programa de Pós-Graduação em Comunicação da Universidade Municipal de São Caetano do Sul (USCS), São Caetano do Sul - SP, Brasil. E-mail: mathfelske@gmail.com. Mestre em Comunicação da Universidade Municipal de São Caetano do Sul (USCS), publicitário pela mesma Instituição. Integrante do grupo de pesquisa Smart Media \& Users (CNPq).

v.20, n. 43 [45-72] maio-ago 2019 